\title{
The challenge of transformation: Breaking the barriers
}

\author{
W.P. Esterhuyse* \\ Graduate School of Business, University of Stellenbosch, \\ PO Box 610, Bellville 7535, Republic of South Africa \\ wpe@belpark.sun.ac.za
}

Received August 2003

\begin{abstract}
One of the most commonly used concepts in post-apartheid South Africa is undoubtedly the concept 'transformation'. In order to strip this concept of its 'bewitchments' (Nietzsche; Wittgenstein) a conceptual analysis is made of the meaning and usage of the term. In view of the distinction between first order change and second order change, the need for transformation (ethical and strategic), the resistance against transformation (systemic and individual) and the execution and management of transformation is discussed.
\end{abstract}

*To whom all correspondence should be addressed.

\section{Introduction}

The concept of 'transformation' has become a symbol of South-Africa-in-transition, signifying the dramatic changes which have taken place since 1994 in the country's traditional relations of power and privilege. Whether in politics, education, social life, health care or business, the vision of a transformed South Africa inspires policymaking, strategic thinking, project planning and a variety of other functions and activities.

The vision of transformation, however, does not represent a South African invention. Transformation is a global phenomenon, encompassing many spheres of life. As Levy and Merry (1986, ix), writing about organisations, have pointed out: Transformation is the strategic response to the condition 'in which an organisation cannot continue functioning as before. In order to continue to exist, it needs a drastic reshuffling in every dimension of its existence.' The same can be said about a country, its institutions, its sets of law and its regulatory systems. Under certain conditions, mainly of a strategic and moral nature, transformation becomes necessary and inevitable. As will be shown, however, 'reshuffling' is not an appropriate metaphor to explain the process of transformation.

In this article the following questions will be addressed:

- What is transformation all about? What do we mean when we employ the concept in a language game on change?

- Why does a country or organisation need to be transformed? What are the justifications, generally speaking, for transformative interventions?
- Is acceptance of transformation something which we can take for granted? For what reasons do people resist or accept transformation?

- How should we manage transformation? What are the general guidelines which should govern transformative interventions?

\section{What is transformation?}

For a number of reasons the concept 'transformation' has become a politically bewitching term in South Africa. This state of affairs illustrates what philosophers, such as Friedrich Nietzsche and Ludwig Wittgenstein, have described as the dangerous and even tyrannical dimension of language: metaphors - the 'tools' of language - becoming stale gatekeepers to the world of created meanings, while, at the same time, ensnaring the users thereof in dogmatic and one-sided interpretations. Hence the need for conceptual clarity, resisting the temptation 'to misrepresent to ourselves the way in which we really use words' (Kenny, 1989).

In an attempt to liberate the meaningful usage of the term from its bewitchments, it is from the outset necessary to keep cognisance of the fact that, although we talk change when we talk transformation, we do not talk any kind of change.

The phenomenon of change, whether in the cultural or natural world, has intrigued mankind for many centuries. The ancient Greeks, for instance, grappled with this phenomenon. Their philosophers tried to identify something which remained the same in the midst of an ever-changing natural and cultural environment. This endeavour reflected mankind's uneasiness with the phenomenon of change and the yearning for something constant, certain and stable. In fact, at one stage of the Western World's history the ideal of certainty was equated with stability. Change, on the other 
hand, was experienced as something negative. The emphasis on 'principles' in Western thought, and the view that 'principles' are timeless, is a legacy of the ancient Greeks.

Among the ancient Greek philosophers Heraclitus became well-known for his philosophy of change, his acceptance of change as a fact of life and his positive evaluation of this phenomenon. Some Roman thinkers did the same. Marcus Aurelius, for instance, advised his readers to get used to thinking that there is nothing 'nature' loves so well as to change existing forms. 'Change' was also the subject of reflection of eminent philosophers such as Hegel, Marx and Nietzsche.

The outcome of these and other reflections was the insight that the concept 'change' is a multi-dimensional concept. It refers to a variety of prototypes - ranging from minor alteration to radical transformation. Although being a part of everyday life, change manifests itself at different levels in our environment.

In the world of nature, for instance, it is usually experienced as a struggle for survival. Organic change, as it is called (Gallias, 1992 14), constitutes a form of adaptation. Species survive, so it is argued, because they display an ability to modify themselves over a period of time under certain circumstances in order to adapt to their environment. Organic change, in other words, is a form of evolutionary change. Its success is determined by the adaptability of the species in question.

In the human and cultural world - the worlds of politics, economics, social interaction, organisations, institutions and created structures - the word 'change' generally speaking, functions as an umbrella term for two very distinct processes triggered by human interventions. They differ in terms of the nature of the strategic interventions, the objectives of the interventions and the outcomes of the interventions.

Some writers (Bate, 1994:33) refer to these interventions as 'strategies for order and continuity' and 'strategies for change and discontinuity'. The processes can be referred to as first order change and second order change.

\section{First order change: conforming strategies}

In the case of first order change, the system itself, including its basic structure, culture and defining values, does not change. The change process takes place within the confines of the system itself, and in terms of the basic principles and values of the system. The main purpose of the intervention is to preserve the fundamentals of the existing order of things by changing the non-fundamentals. Change amounts to differentiations in forms of behaviour.

This category of change is usually referred to as adaption, renovation, adjustment, incremental change or piece-meal engineering. The objective is to change behaviour within a prevailing system without affecting the basic structure, culture and defining values of the system. Change is moreover regarded as an evolutionary process.
Paul Bate (1994:35) refers to those who pursue this strategy as 'culture conservationists' who wish 'to preserve and protect the cultural environment (the order) that their predecessors or present-day 'elders' have created'. They act 'like people on the deck of a ship who lean one way, then the other, in order to counteract the movement of the waves'. Their message is: do what you do best, better and more often.

Martel (1986:18) points out that this prototype of change is not necessarily unproductive. Distinguishing between cyclical change - which falls within the ambit of first order change - and structural or second order change, he points out that the former occurs on the operational levels of institutions. Cyclical change may also occur within the economic system of a country. In the case of organisations it may become necessary to intervene on the operational level of an institution or system in order to prevent stagnation and enhance efficiency, by, for instance, decentralizing management systems and streamlining bureaucratic procedures. This could be done without changing the basic structure, culture and defining values of the system.

First order change is limited and temporary in duration. It may, for instance, become necessary to decentralise operations for the sake of efficiency, and at a later stage, to reintroduce centralised forms of operational management for the sake of better control.

\section{Second order change: transforming strategies}

Second order change is of a more radical nature. Its primary objective is not to intervene in the operations of an organisation but to transform its basic structure, culture, defining values and overall form. Martel (1986:18) quite rightly refers to this prototype of change as structural change, emphasising the fact that a fundamental transformation of an organisation's total make-up is on the agenda.

Bate (1994:16), in order to underline the decisive nature of second order change, coins the phrase 'form- or framebreaking' indicating thereby the distinctive character of transformative strategies. Strategies aimed at transformation inevitably break the evolutionary chain of development, creating discontinuity and variance of form. Put differently, transformation means a new organisation, a new structure, a new culture, new core values and a new direction.

From what has been said so far it should be clear that the concepts structure, culture and defining values refer to key elements of second order change. These concepts form a family relationship and cannot be discussed as separate 'entities', a methodological mistake commonly made. Translated into strategic terms: it is impossible to change the basic structure of an organisation without changing its culture and defining values.

Structure, generally speaking, refers to visible and invisible organisational patterns. These patterns may be of a hierarchical nature. They could also be 'flat'. We could describe them as authoritarian or as democratic and participative. Structures and patterns reflect not only the 
overall form of the institution but also the network of relationships that constitute the institution. Structures, patterns and relational networks have a direct bearing on communication within an institution, and on feelings such as loyalty or disloyalty, belonging or alienation.

The culture of an institution is the 'glue' of the structure. It includes the artefacts, stories, myths, symbols, language games, conventions, traditions and thought patterns of the institution. Hence organisational culture directly influences the way people behave in an institution, for it represents the pattern of basic assumptions in terms of which a given group has learned to cope with problems and challenges (Schein, 1983).

The defining or core values of an institution - whether these values are instrumental (efficiency) or existential (justice) guide and shape the way in which an institution fulfils its purpose (Blanchard, 1997:20). They embody the normative dimension of an institution and its activities, defining the motivations, limits and boundaries of behaviour. As such they constitute the ethical climate of an institution as well as the quality of its governance.

Defining values are part and parcel of an institution's culture, something Deal and Kennedy (1982:15) had in mind when they stated rather categorically: 'A strong culture is a system of informal rules that spells out how people are to behave most of the time'. Values give meaning and direction to a person's behaviour, enabling him or her to experience work as a form of fulfilment and to identify with an organisation.

Second order change, or transformation, affects the patterns and values in terms of which people tend to behave, turning traditional habits and routine responses upside down. For this very reason transformation inevitably creates uncertainties and conflict.

A decisive aspect of transformation is that it goes hand in hand with a mindset change or paradigm shift. We act and think in terms of frames of reference or paradigms, illustrated by the very commonly used justification: this is the way I have always done it. Huey (1991: 91) makes the valid point: 'a paradigm - in its business connotation - is simply the conventional wisdom about how things have always been done and must continue to be done'.

Mindsets, frames of reference or paradigms reflect our prejudices, our values, our beliefs and our social conditioning. They can be 'hard', or dogmatic - in the sense that they condition us to cling to them for better or for worse. They also can be 'soft' - displaying our willingness to change and to explore new possibilities.

Transformational change is ignited by a new way of thinking; a conceptual change that opens up new perspectives on the world. This is the reason why stale paradigms restrict us from thinking differently about issues and problems, locking us up in a very particular way of seeing a problem. In this way stale paradigms limit the range of solutions that can be applied as well as the decisions one can take. Hence paradigm shifts represent 'switching cognitive gears' from an automatic habit of mind to active, conscious reflection (Louis \& Sutton, 1989).

Accepting a new paradigm requires a period of transition. Kuhn (1962:7), writing about paradigm shifts in science, makes the valid point that a paradigm shift 'is seldom completed by a single man and never overnight'. To initiate a paradigm shift there has to be 'a divine discontent with the status quo at the very top, and the courage to do something about it' (Huey, 1991: 91).

Whatever the case may be, paradigms 'mould' the way in which we look at things, or experience the world and each other. More often than not paradigms restrict our vision and understanding, limiting our capacity to come up with creative solutions. Transformers and paradigm shifters are therefore usually 'highly opinionated, action-oriented types whose speciality is ... rocking the corporate boat' (Huey, 1991:91). They are 'innovators', 'creators' and 'inventors' rather than 'imitators', 'copiers' or 'improvisers' (Bate, 1994:35). That is why they often do not survive a process of transformation. They do not believe in evolution but are driven by a revolutionary élan.

It should be obvious by now that if we want to take transformational change seriously it is of paramount importance to consider questions such as:

- How do we perceive our environment? What are the positive and negative driving forces, the defining tensions and the breakpoints?

- What are the defining characteristics of our organisation, its basic structure, culture and value system?

- Do we have a clear picture of the ruling mindsets or paradigms governing organisational behaviour?

\section{The need for transformation}

Generally speaking, the need for transformation is linked to what has been happening globally for the past fifteen to twenty years: the emergence of a networking world, a world of continuously changing links (both technical and human). We live in a world driven by the information revolution and the technologies based on this revolution. In order to stay in business and remain competitive, organisations of the postmodern world have to employ new technologies.

It is generally accepted that organisational mortality will be very high in the emerging new world. Organisations wanting to remain the same as they were in the past, following the recipe for success of bygone days, will be wiped out completely. The post-modern world is a highly competitive one in which the successes of the past do not guarantee future success. Ensuring organisational survival in such an environment will be no easy task. Organisational survival is furthermore complicated by the demand on organisations to release things of value to interested parties. 
These pressures on organisations have been exacerbated by a number of 'displacements' which have taken place over the last 15 years. In fact, the traditional production-oriented and volume-driven culture has already been displaced by a customer-oriented and quality-driven culture. Coupled with this displacement, we are witnessing a break with hierarchical systems as well as with the concomitant topdown approach to decision-making. Customer democracy, the emergence of issue-driven activism, acceptance of triple bottom line thinking (financial; environmental; social) and the need for sustainable development have displaced most of the traditional values and justifications of orthodox capitalism.

In South Africa the global need for transformation is linked to country-specific socio-economic and political considerations. The most important of these are of a moral and strategic nature.

The moral perspective should be obvious: how to transform a racially based economical and organisational pattern, a legacy of the past, into a commonly shared, open and nonracial, as well as non-sexist, pattern? The main objective of structural change inspired by a moral perspective is to establish legitimacy and moral acceptability. Without legitimacy no institution can survive in the long run.

This is no easy task, given the fact that discriminatory patterns and practices in South Africa are not merely of a co-incidental nature but stem from structural conditions. These conditions have created vested interests as well as 'entrenched' mindsets or paradigms on both sides of the racial divide.

Apartheid, as an ideology (racial oligarchy) as well as a system of institutionalised and legalised racial discrimination, was in its core values immoral. Racial discrimination was not a mere political policy, or a set of reasonably coherent and consistent policy measures with which acceptable political aims were being pursued. On the contrary, apartheid was in its structure, policy means and policy aims morally unacceptable. It represented structural racial discrimination. Its immoral character was of a systemic nature. Hence apartheid could not just have been 'abolished' by cancelling laws and regulations. Still less could it have been done away with by merely getting rid of the masters of apartheid, replacing them with others. It could only be abolished by transforming the basic structure, culture and core values of apartheid in order to liberate South Africa from the legacy of apartheid. It is a complex and multi-faceted process.

One of the issues on the agenda is equitable access to scarce resources, opportunities and skills. Related to this issue is the need to establish cross-cultural and cross-racial economic alliances in order to stabilise the country politically and socially, establishing a deracialised middleclass as well as dealing effectively with poverty. At present affirmative action and black economic empowerment are some of the procedures utilised to address these issues. In this respect it should be noted that affirmative action and black economic empowerment do not constitute the full scope of transformational structural change. In the South
African context, in particular, they represent specific aspects of transformation, albeit important moral and political aspects. Transformation, however, entails much more than affirmative action or black economic empowerment.

This becomes clear when on analyses the strategic perspective of transformation within the South African context.

Without going into the detail of South Africa's political and social environment, it should be noted that socio-economic inequalities and extreme levels of poverty are some of the strategic challenges facing the country. Democratising South Africa, and setting up viable structures embodying the vision of a non-racial and non-sexist democracy, is a laudable strategic objective. This objective, however, should be underpinned by strategies aimed at alleviating the plight of the poor, effectively addressing socio-economical inequalities and establishing a thriving economic environment. In a strategic nutshell: a stable and viable democracy in South Africa is dependent on vigorous (people) development and economic growth. To this end the structural transformation of South Africa is inevitable.

Much progress has been made in this regard. The policy document on 'Growth, Employment and Redistribution' (Gear), combining economic growth strategies and reconstruction and development strategies, was a major achievement. The outcome of the implementation of these policies and strategies will have a decisive impact on South Africa's future political and social stability.

The important point emphasised by the foregoing is that the concept 'transformation', strategically applied to the South African context, does not refer to the domain of politics only. In fact, it would amount to a strategic blunder if the transformation of South Africa is viewed solely from a restrictive political perspective. A holistic perspective is best suited if one talks about South Africa's transformation.

In this regard it should also be emphasised that transformation includes much more than establishing legitimacy for institutions and organisations. Transformative interventions also have to enhance performance, productivity, efficiency and competitiveness. Transformation is about a new and better order of things.

These and other strategic challenges necessitate a view of transformation that surpasses the narrow political definition. It is therefore in the strategic interest of every South African, rich and poor, white and black, that a well-planned and thoroughly executed vision of transformation should succeed in order to make South Africa a winning country.

Of course, what pertains to South Africa as a country, its institutions and policy frameworks, also pertains to private sector organisations.

Transforming a country, its institutions and its organisations is no easy task. Transformation creates uncertainty among those who have profited from the old order of things, as well as high levels of expectations from those who have been excluded from the corridors of power and privilege. How to 
manage these uncertainties and expectations poses a serious challenge.

Bate (1994:82) is worth quoting at length when he justifies the transformation of organisations from the perspective of the 'exhausted soil' of culture (Simmel): 'Not only has the culture lost its creativity and vitality, and its ability to touch hearts and minds, it has also lost its direction: what was once a progressive linearity of development has become a regressive circularity of development; the 'virtuous' circle, with its infinite capacity for generating new combinations of the cultural material, has become a 'vicious circle' - a whirlpool or spiral of narrowing options and endless repetitions of constantly failing solutions: a framework of opportunities has become a framework of constraints. The strategy-in-use has become a strait-jacket ...'

\section{Resistance against transformation}

Resistance against transformational change usually occurs on two distinctive levels:

- the systemic level; and

- the individual/psychological level.

\section{Systemic factors}

Systemic factors are related to the institution itself. When embarking upon a planned programme of transformation it is therefore necessary to consider the built-in factors which impact negatively on transformational change. Some of the factors which most institutions have experienced as changeresistors are the following:

- a hierarchical organisational structure, and the concomitant obsession to maintain existing relations of power and control;

- non-participative decision-making procedures (oneman rule);

- an obsession with short-term gain/profit and taskoriented behaviour;

- $\quad$ the equation of survival - and remaining in business with stability.

Many institutions have an in-built conservatism and preservation syndrome. The reason for this state of affairs is to be found in a typical characteristic of organisational life: regularised patterns of behaviour. This is what organisational life is all about - acting in an organised manner. Often these patterns of behaviour lead to the view that stability is a necessary condition for survival. Transformation, on the other hand, is regarded as the destruction of customary patterns of behaviour. This is why writers such as Moerdyk and Fone (1988) can say that any change that interferes with the normal patterns of work will generally be resisted, because old habits and routines have to be 'unlearned' and new ones acquired.

\section{Individual factors}

Writers on the subject of the individual's response to transformational change list a wide variety of factors playing a role ranging from political factors to social and psychological factors. The following are some of them:

\section{Perceived self-interest}

At one or other stage in the process of transformation one has to deal with a conflict of interest between the institution's need to transform itself and the individual's perception of her/his vested interest. Groups of people may even display high levels of solidarity in their resistance against transformational change. It usually occurs when they share the conviction that their vested self-interests are collectively threatened by the transformation. Consequently 'Group-thinking' takes over, as well as informal (subtle) and formal (organised) resistance to change.

In this regard it is important to note that writers on the subject of transformational change point out that an individual's acceptance of change stands in a direct relationship to his/her perception of the benefits which will accrue to him/her from the transformation.

\section{Feelings of fear and uncertainty}

Dramatic change inevitably generates conflict on various levels. As far as individuals are concerned, it not only creates conflicts of interest but also feelings of insecurity. The reason for this is obvious: confrontation with the 'unknown' and, subsequently, the view that one or other loss is imminent.

During times of transformation and transition the future becomes a 'moving target', (Pierre Wack), whilst the present is characterised by ambiguities. How to manage the fears and insecurity of people during transformational change hence poses a daunting challenge.

An interesting point made by Hofstede (1984) is that many people display an 'Uncertainty Avoidance' attitude when confronted by the ambiguities of transitional processes. Those with a strong 'Uncertainty Avoidance' attitude manifest a very high level of intolerance towards transformational change. Their defensive strategies include a very rigid position on the maintenance of traditional beliefs, conventions and codes.

\section{Conservatism}

Conservatism may be political, cultural or even intellectual. In the latter case, acquired skills and knowledge are regarded as sufficient. Transformation is viewed as a threat to acquired skills and knowledge. Hence the tendency to protect - and justify - the status quo.

The danger of conservatism is that it may lead to a situation in which an individual agrees in public to the idea of change but retains his/her prejudices and beliefs in private. The institutionalisation of change (systemic change) does not 
necessarily lead to internalised change. People may, in a variety of subtle ways, try to preserve the status quo by undermining or discrediting change initiatives.

\section{Initiating and managing transformation}

The literature on this very important dimension of transformation, has expanded in a dramatic manner since the eighties. An important factor in this regard was the emphasis on culture in an organisation's demise - or in its performance and competitiveness (Davis, 1985; Deal \& Kennedy, 1982).

It is not possible - or necessary - to go into the details of the theoretical and strategic-practical perspectives defended by various writers on transformation. A generalised overview, focusing on some of the main points of consensus which have emerged over the last decade, will have to suffice.

Paul Bate (1994: 202-210), following Mintzberg's (1979) example of design parameters for structural change, and drawing on research by a number of other writers on the subject, proposes five design parameters for cultural change that represent a widely-held consensus. The parameters are developed with the view of accommodating specific components of an institution.

'Expressiveness' is the parameter which addresses the 'affective component' of the institution. It summarises the need to present a 'core' or founding idea '... that has the power to 'move' people' (Bate, 1994:205). Whatever the specific strategic approach to transformation may be, it must include a core idea which will 'excite', 'energise', 'activate' and 'disturb' people, capturing their attention.

The second parameter, 'commonality', addresses the 'social component (relationships)' of an institution. This core idea must become part and parcel of the 'collective imagination of the whole community' (Bate, 1994:207), bringing about 'linguistic homogeneity', shared responsibility, a community of purpose, common ownership of the idea and shared values.

The third parameter is 'penetration', or a strategic approach which has the capacity to permeate different levels of an institution. This parameter has the 'demographic component' of an institution in mind.

'Adaptability', focusing on the 'developmental component' of an institution, reflects the need for a strategic approach which has the flexibility to adapt to the changing circumstances.

The 'institutional component' of an institution, or its structural pattern, is covered by the parameter of 'durability' - the ability of a strategic approach to create a culture that will be lasting within the limits of legitimacy and efficiency. This particular parameter also includes the need to initiate a transformative process which will acquire momentum and become irreversible.

An important point made by Bate is that transformative strategies may indeed vary, depending on the nature and needs of the institution to be changed as well as on the context in which the transformation has to take place. What should be borne clearly in mind, however, is that whichever strategic option is elected, the abovementioned design parameters must function as guiding lights in order to effect a successful transformation.

Of the strategic approaches available to a transforming leader, the following could be mentioned.

Firstly, a comprehensive and in-depth diagnosis of the organisation's prevailing culture and structure. The diagnostic facet of a strategy aimed at creating second order change is of prime importance for it paves the way towards understanding the justification, the direction, the magnitude, the pace and even the duration of the transformative intervention.

Secondly, a trigger-phase to kick-start the process. In an article, significantly entitled: 'Transformational and coercive strategies for planned organisational change: beyond the O.D. model', Dunphy and Stace (1988: 321) came up with the startling insight: radical times demand radical remedies. They pointed out that chief executives, ditching the step by step and sensitive approach, tend to opt for the coercive dictate.

This approach to the triggering of second order change has its advantages and disadvantages. One advantage is that transformation could be linked to set deadlines, especially as far as the initial phases of the process are concerned. It also creates scope for timeously seizing the initiative, not wasting time on lengthy discussions of alternatives or allowing for stalling tactics by conservatives. In typical militaristic jargon, but not without some good reasons, Foster (1986) refers to the triggering dimension of transformative interventions as 'the attacker's advantage'.

Disadvantages of the coercive dictate approach is that it excludes broad participation in decision-making, limiting acceptance of the initiated change to external conformance which, in turn, depends on external control systems and constant monitoring by management. For this very reason negative reactions and even disloyalties are usually provoked among those not directly involved in the managing of the trigger-phase itself.

Transformation requires something else: visionary and persuasive leadership. In many instances problems arising from transformative interventions have little to do with the attitude of people. They are, invariably, managementcreated problems and the outcome of the leadership's inability to deal with transformational issues in a visionary and persuasive manner.

The leadership displayed during transformation, and the ability of those involved to influence people, will determine whether the envisaged changes will eventually become internalised. In most examples of successful transformation, it was in the final analysis the scale of internalisation which led to a decisive transformation of the institution's culture. The fact of the matter is that internalised transformational change is also self-maintaining. Or, formulated differently: 
Transformation on the institutional level without internalisation remains hollow and has to be kept on track by coercive measures or external sources. This is one of the reasons why the need for transformation should be communicated by a change agent with credibility, justifying the intended changes as necessary for addressing a serious problem.

One has to accept that transformation, especially during the trigger-phase, generates all kinds of conflicts and uncertainties within organisations. Some of these conflicts may remain on the agenda for quite some time. Certain types of conflict may be classified as creative and constructive. Others may be of a destructive nature. A distinction can even be drawn between legitimate and nonlegitimate types of conflict.

These and other problems facing the transformer, imply that the trigger-phase should, from a strategic point of view, include steps aimed at facilitating a participative process. Broadly speaking, these steps include: the generation of new and creative ideas which would activate and carry the (new) vision of the organisation; consensus on the values which should strengthen the organisation's vision; clarifying the purpose and strategy of the organisation, as well as strengthening the collective commitment to that purpose and strategy; identifying priorities and developing action plans aimed at effectively dealing with priorities. The objective of this is to involve at least the key players in the process of transformation.

In a very illuminating article, 'Corporate culture and strategic change', Hassard and Sharifi (1989: 12; 13) make the following point: 'Managing the deepest layers of culture requires a participative approach ...'. And the reason? 'Topdown approaches yield changes that are relatively easy to bring about, but which are difficult to sustain ...'. Sashkin (1984) even argues: 'Participative management is an ethical imperative'. And Sanford, Hunt and Bracey (1976), writing about communications behaviour in organisations, are of the opinion that an interactive approach is best suited to goal setting, motivation, interaction among levels, communication and innovative decision-making.

The main assumption of these and other views on a participative approach, is contained in a remark made by Wilkens (1989:16) in his challenging article on the issue of: How to successfully change an organisation without destroying it. Stressing the point 'you cannot buy a distinctive organisational culture and you cannot copy it from someone else', he concluded: 'You must grow it'. Although the growth-metaphor is not without its own flaws, for instance unintentionally conveying the message that continuity and evolutionary development is what it is all about, the main intention of Wilkens is to metaphorically articulate the view that the creation of an organisation's culture or network of symbolic meanings, is not a one-man show, but a collective endeavour. How to initiate, lead and manage the collective endeavour, or the challenge to collectively establish a motivating consensus on meanings, is hence of primary concern to those supporting an interactive approach.
Louis (1989) makes the very valid point that, in order to be truly participative, a cultural learning process should be initiated. In such a process participants are motivated to actively construct - and conceptualise - the new organisational culture. In other words, a new culture is neither taught to participants nor imposed by those in authority. Participants are led to discover and eventually give form to the new culture. This means that training during periods of transition should not be degraded to indoctrination. It should be conducted as a form of collective discovery and learning - keeping in mind the design parameters discussed earlier on.

\section{Conclusion: Leadership}

By now it should be quite clear that transformation is a complex process and something not to be embarked on lightly or without careful reflection and thorough strategising. During its initial phases it inevitably has a destabilising effect, generating uncertainties, resistance and conflict.

One of the main reasons for this state of affairs has been emphasised repeatedly: the inhibiting role played by an organisation's orthodox culture, and the fact that culture - in its stabilised and apparently solid form - functions as a safe haven or unassailable castle. Harvey-Jones, one-time chairman of ICI - while reflecting on the issue of leadership - coined a phrase which is on the spot if one wants to characterise an orthodox culture: 'collective blindness' (1989:78).

What he has in mind is the inability of those managing a company to understand the need for transformation. And this inability is generated by the firm grip of the orthodox culture of the company on the minds of managers, preventing them from seeing the world and their environment in a new manner. Entrenched in their cultural castle or, put differently, their cultural scheme of interpretation, they are not so much unwilling to see things differently as they are unable. Unable to even spot the defects of their own organisation, they remain the prisoners of their past successes.

The answer to the question how 'collective blindness' can be remedied, is as clear as crystal: it is only by transformation of the organisation's culture and, with that, its defining values, vision and strategy.

Transformation, as a process which should lead to a new structure, culture and system of defining values, requires visionary leadership. Burns (1978) specifically refers to transforming leadership - in contrast to transactional leadership where support for the leader is organised through political transactions, for instance through the allocation of positions of power instead of being generated by means of a mobilising vision and commitment to values. Transforming leadership, it could even be argued, is more important than orthodox management when one has second order change in mind, a point emphasised by writers such as Bennis (1981) and Conger (1991). 
This point, however, should not lead to the misconception that transformation is a one-person show or that visionary leadership is exclusively an individual activity. The transformer cannot go it alone but has to mobilise networks of leaders, especially 'informal' leaders, in order to make second order change happen. In some instances informal leadership networks are more decisive than formal networks in writing a transformational success story.

Conger (1991:31) articulates the significance of leadership during times of transition and transformation extremely well when he wrote: 'While we have learned a great deal about the necessity of strategic vision and effective leadership, we have overlooked the critical link between vision and the leader's ability to communicate its essence. In the future, leaders will not only have to be effective strategists, but rhetoricians who can energise through the words they choose'.

After everything has been said and done about transformation, it has to be emphasised strongly that without vision, and value-driven leadership, transformation will remain blind. And a discussion of transformation without a discussion of leadership - and what transformation leadership entails - is empty. While it has to be accepted that transformation for strategic and moral reasons is South Africa's bridge to the future, it unfortunately also has to be accepted that too little attention is devoted to the question of what kind of leadership is needed to effect cultural change.

\section{References}

Baker, E.L. 1980. 'Managing organisational culture,' Management Review, 69 (7):8-13.

Bate, P. 1995. Strategies for cultural change. London: Butterworth/Heinemann.

Bennis, W. 1981. 'The artform of leadership.' In Srivastra, S. et al. (Eds.). The executive mind: New insights on managerial thought and action. San Francisco: Jossey-Bass.

Blanchard, K. \& O'Connor. M. 1997. Managing by values. San Francisco: Berrett-Koehler Publishers.

Burns, J.M. 1978. Leadership. New York: Harper \& Row.

Conger, J.A. 1991. 'Inspiring others: The language of leadership', Academy of Management Executive, 5(1): 3145 .

Davis, S.M. 1984. Managing corporate culture. Cambridge (Mass): Ballinger.

Deal, T.E. \& Kennedy, A.A. 1982. Corporate cultures: The rites and rituals of corporate life. (Mass.): AddisionWesley.

Foster, R.N. 1989. Innovation: The attacker's advantage. New York: Summit Books.
Gallias, J. 1992. 'Mastering organisational change and conflict'. University of Pietermaritzburg. Unpublished MA manuscript.

Hassard, J. \& Sharifi, S. 1989. 'Corporate culture and strategic change', Journal of General Management, 15(2):419.

Hofstede, G. 1984. Culture's consequences. Beverley Hills: Sage.

Huey, J. 1991. 'Nothing is impossible', Fortune Magazine, Sept 23:91-96.

Kenny, A. 1989. 'Ludwig Wittgenstein: Why do philosophy if it is only useful against philosophers?' The Times Higher Educational Supplement, 19 May.

Kuhn, T. 1962. The structure of scientific revolutions. University of Chicago: Chicago Press.

Levy, A. \& Merry, U. 1986. Organisational transformation. New York: Praeger.

Louis, M.R. 1989. 'Newcomers as lay ethnographers: Acculturation during organisational socialisation', Working Paper, Boston University.

Louis, M.R. \& Sutton, R.I. 1989. Switching cognitive gears: From habits of mind to active thinking. Working Paper 89-1. Boston University.

Martel, L. 1986. Mastering change: The key to business success. London: Grafton Books.

Mintzberg, H. 1979. The structuring of organisations. A synthesis of the research. NJ Englewood Cliffs: PrenticeHall.

Moerdyk, A. \& Fone, J. 1988. 'Resistance to change. Its origins and management,' IPM Journal 1:14-17.

Sanford, A.C., Hunt, G.T. \& Bracey, H.J. 1976. Communications behaviour in organisations. Ohio: Charles E. Merrill.

Sashkin, M. 1984. 'Participative management is an ethical imperative', Organisational Dynamics, Spring.

Schein, E.H. 1984. 'Coming to a new awareness of organisational culture', Sloan Management Review, Winter.

Wilkens, A.L. 1989. Developing corporate character: How to successfully change an organisation without destroying it. San Francisco: Jossey-Bass. 